\title{
Geoprocessamento aplicado ao monitoramento dos índices de criminalidade no agreste meridional de Pernambuco
}

\author{
Felippe Pessoa de Melo' \\ 'Universidade Federal de Sergipe, São Cristóvão,Brasil
}

\section{Resumo}

O Agreste Meridional pernambucano é formado por dezoito cidades, dentre elas Garanhuns e Lajedo ocupam um local de destaque em relação aos altos índices de crimes violentos letais intencionais (CVLI). Utilizando o sistema de informações geográficas (SIG) ArcGIS, em consonância com os dados vetoriais do Instituto Brasileiro de Geografia e Estatística (IBGE), mais as informações do Programa das Nações Unidas para o Desenvolvimento (PNUD), foi confeccionado um banco de dados geográficos, que permitiu a interpolação, análise, interpretação das informações e confecção das cartas temáticas necessárias para espacializar essa dinâmica geográfica.

Palavras-chave: Agreste Meridional; SIG; Banco de dados;

\begin{abstract}
The Southern Agreste Pernambuco comprises eighteen cities. Among them are Garanhuns and Lajedo that occupy a prominent position in relation to the high rates of intentional lethal violent crimes (ILVC). By using the geographic information system (GIS) ArcGIS, in line with the vector data from the Brazilian Institute of Geography and Statistics (IBGE), and the information from the United Nations Development Program (UNDP), a geographic database was made, allowing interpolation, analysis, interpretation of information and preparation of thematic maps required to spatialize this geographical dynamics.
\end{abstract}

Keywords: Southern Agreste; GIS; Database; 


\section{INTRODUÇÃO}

O Agreste Meridional pernambucano é formado por dezoito cidades (Figura 01). Dentre elas Garanhuns e Lajedo são as que apresentam as maiores taxas de crimes violentos letais intencionais. De 2008 ao primeiro semestre de 2013 essa região apresenta uma média anual de 46,22 CVLI. Tendo o ano de 2008 como o mais violento com 203,0.

Os municípios de Garanhuns e Lajedo são os que apresentam as taxas criminais mais elevadas, suas médias anuais de 2008 a junho de 2013 foram de 58,16. Obedecendo ao mesmo intervalo temporal a média de Garanhuns é 42,16 e a de Lajedo é 16,0. Em contraposição a esses elevados índices a cidade de Terezinha possui uma média de 1,16. Destacando-se os anos de 2009 e 2013 (primeiro semestre) sem nem uma ocorrência de CVLI. Essa porção do território pernambucano apresenta um IDH muito baixo 0,308 (Figura 02), seu coeficiente Gini médio é de 0,56 (Figura 03). Essas médias dos indicadores demonstram que as disparidades socioeconômicas possuem uma relação intrínseca com as elevadas taxas de criminalidade.

A interpolação desses dados em um banco de dados geográficos digital em um ambiente de SIG é de suma importância para análise e interpretação dessa problemática social. Logo, essas tecnologias possibilitam materializar esses dados através de cartas temáticas, facilitando a absorção da informação.

O uso de tecnologia de análise espacial, combinada com dados socioeconômicos e ambientais, constitui uma poderosa alternativa para a instrumentalização de políticas públicas de combate à criminalidade urbana. Neste contexto, a apresentação de uma tecnologia integradora e sistemática de captura, armazenamento, consulta e análise de dados referentes à criminalidade urbana, é a finalidade principal deste trabalho, abrindo um leque de visão para as autoridades policiais, demonstrando o uso do Geoprocessamento como uma alternativa de alto valor para o tratamento de questões de segurança pública. (FREITAS \& VIEIRA, p. 2, 2007).

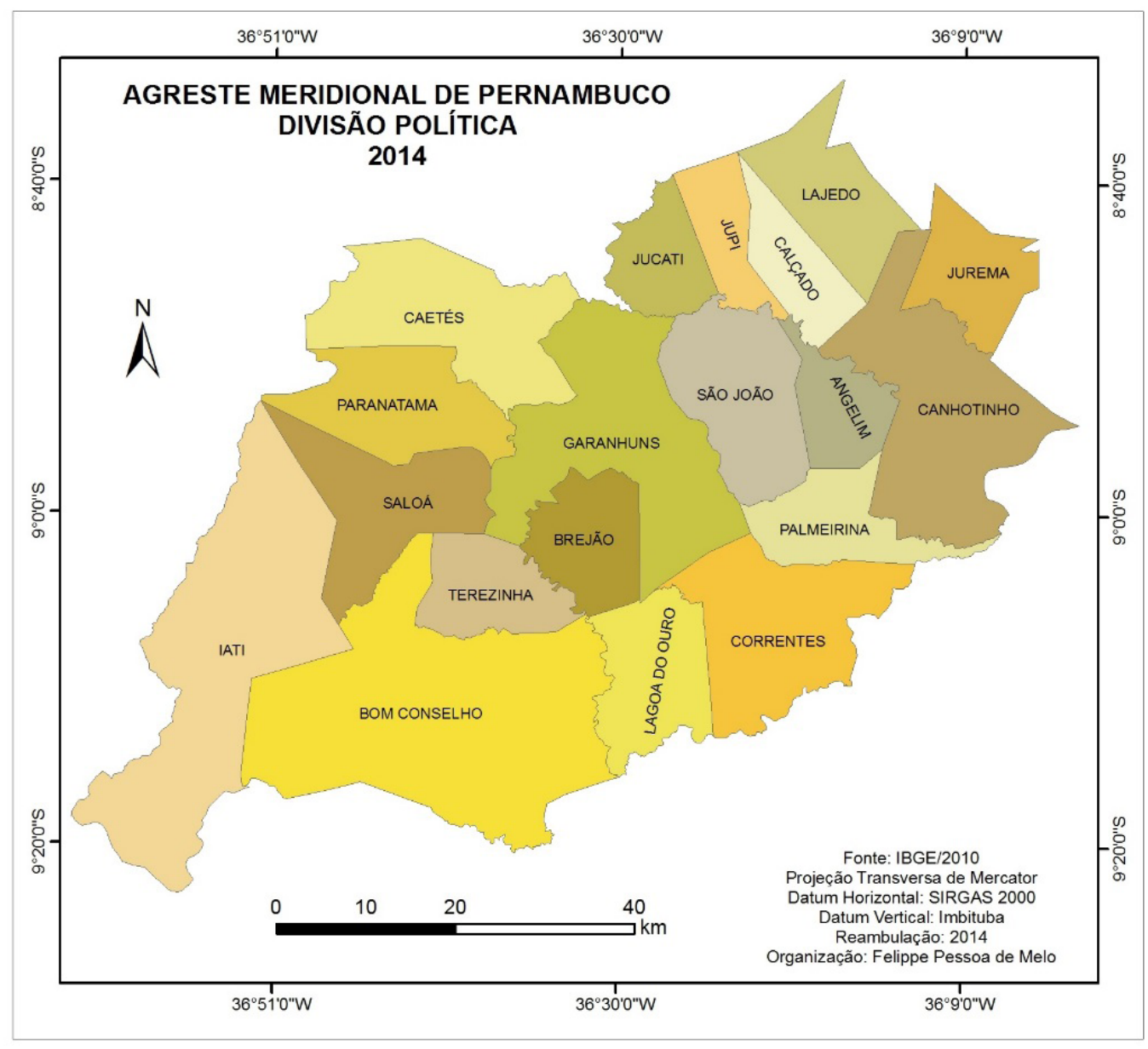

Figura 01. Localização da área de estudo. 


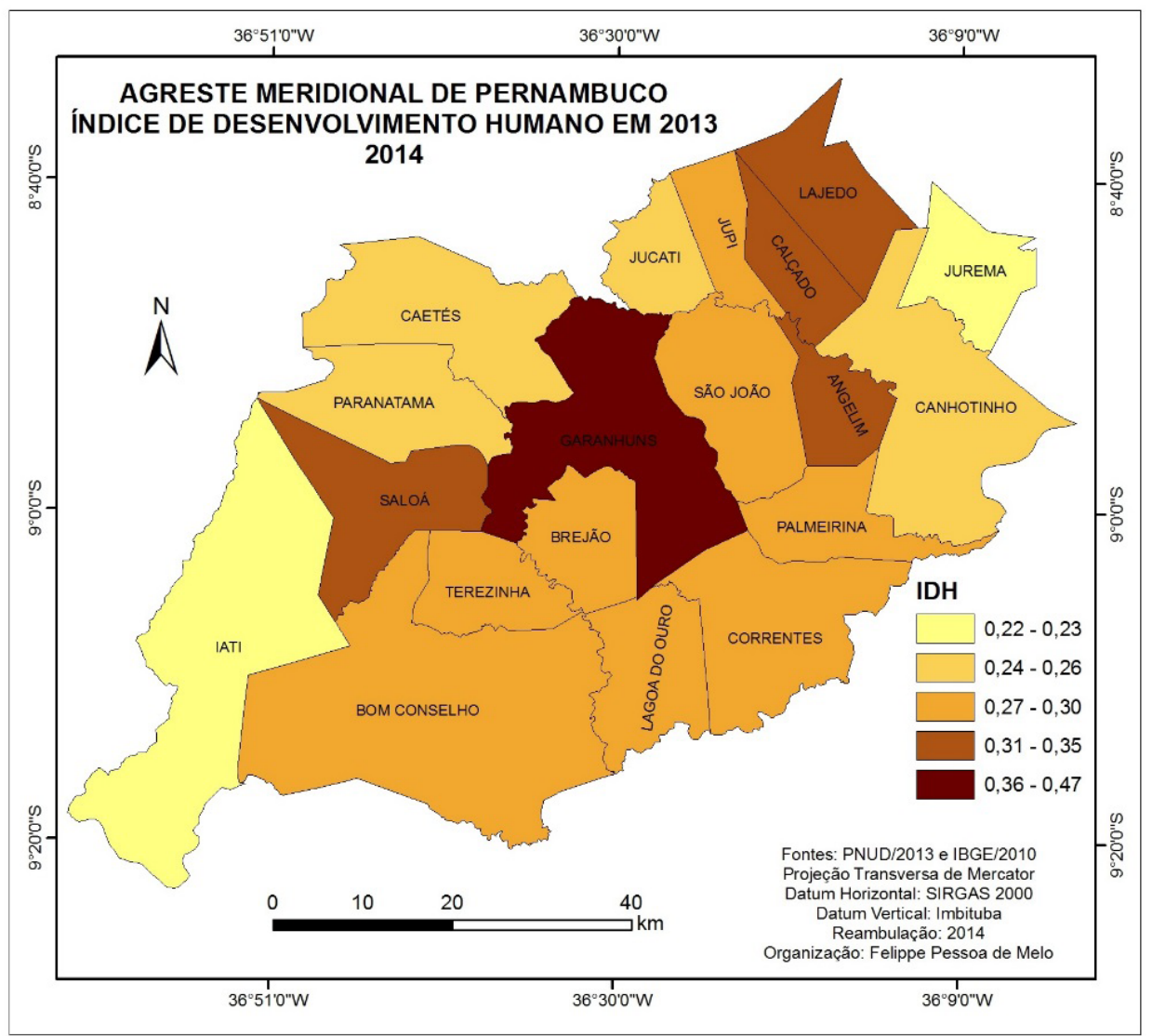

Figura 02. IDH do Agreste Meridional.

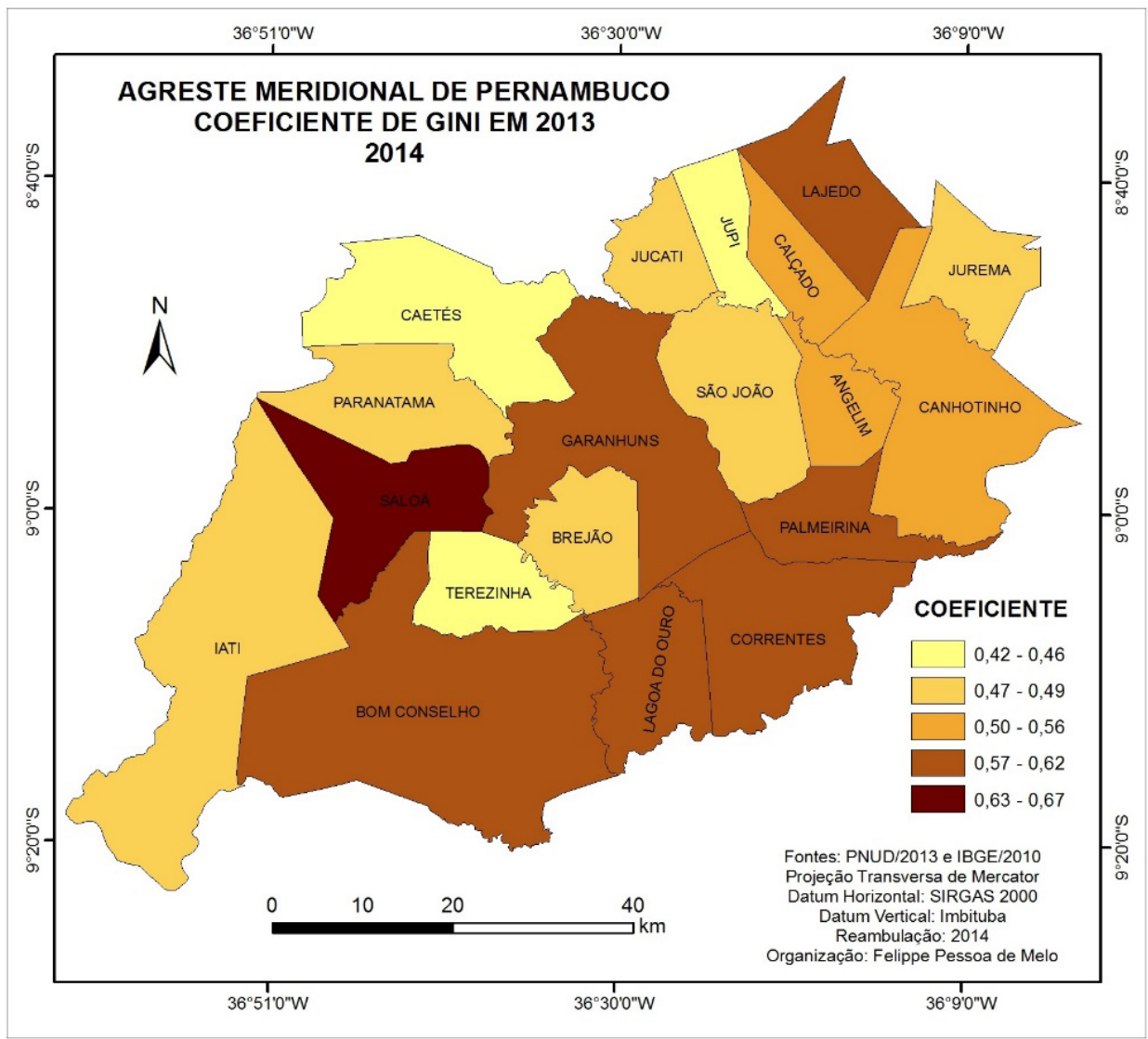

Figura 03. Coeficiente Gini do Agreste Meridional. 


\section{METODOLOGIA}

Foi feita uma pesquisa virtual, objetivando aquisição dos vetores do Instituto Brasileiro de Geografia e Estatística (IBGE) referentes à malha digital do Agreste pernambucano, dados analógicos do Programa das Nações Unidas para o Desenvolvimento (PNUD), pertinentes ao Índice de Desenvolvimento Humano, Coeficiente de Gini e informações em PDF da Secretaria de Defesa Social de Pernambuco (SDS/PE).

Os arquivos em formato shp foram processados no programa Global Mapper, onde o datum (horizontal) original (WGS84) foi substituído pelo datum SIRSGAS 2000, para que as cartas ficassem em consonância com as normas cartográficas brasileiras, e logo em seguida foram exportados no formato shapefile para o banco de dados.

No ambiente do sistema de informações geográficas ArcGIS, os vetores tratados anteriormente foram anexados ao banco de dados e editados para a incorporação dos dados analógicos. Após esses procedimentos foram confeccionadas as cartas temáticas: Crime Violento Letal Intencional em 2008, 2009, 2010, 2011 e 2012; Coeficiente de Gini em 2013; Índice de Desenvolvimento Humano em 2013 e Divisão Política. De posse desse material cartográfico foram feitas as análises e interpretações dos dados cartográficos oriundos do levantamento virtual. O que possibilitou diagnosticar essa dinâmica socioespacial de forma mais fidedigna.

\section{RESULTADOS E DISCUSSÕES}

Em 2008, os municípios de Caetés, Calçado e Terezinha, apresentaram uma taxa de CVLI de 1,0 a 2,0 (Figura 04); no mesmo intervalo temporal, Jurema, Angelim, Palmeirina, Paranatama, Brejão e Lagoa do Ouro, tiveram um índice de 2,1 a 5,0; Iati, Saloá, Jucati e Jupi obtiveram um percentual de 5,1 a 9,0; Lajedo, Canhotinho, São João, Correntes e Bom Conselho, chegaram a um percentual

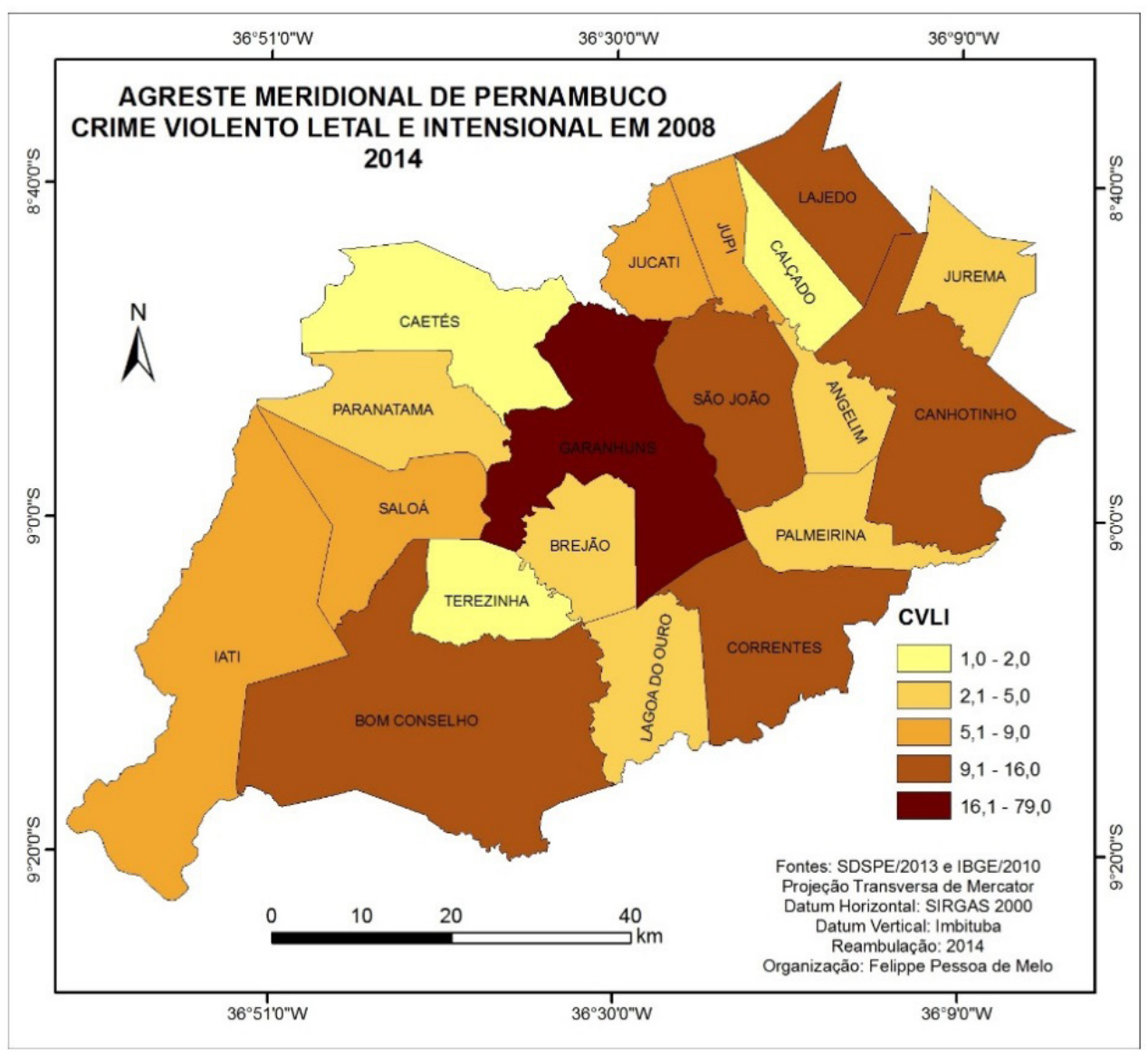

Figura 04. Índice de CVLI 


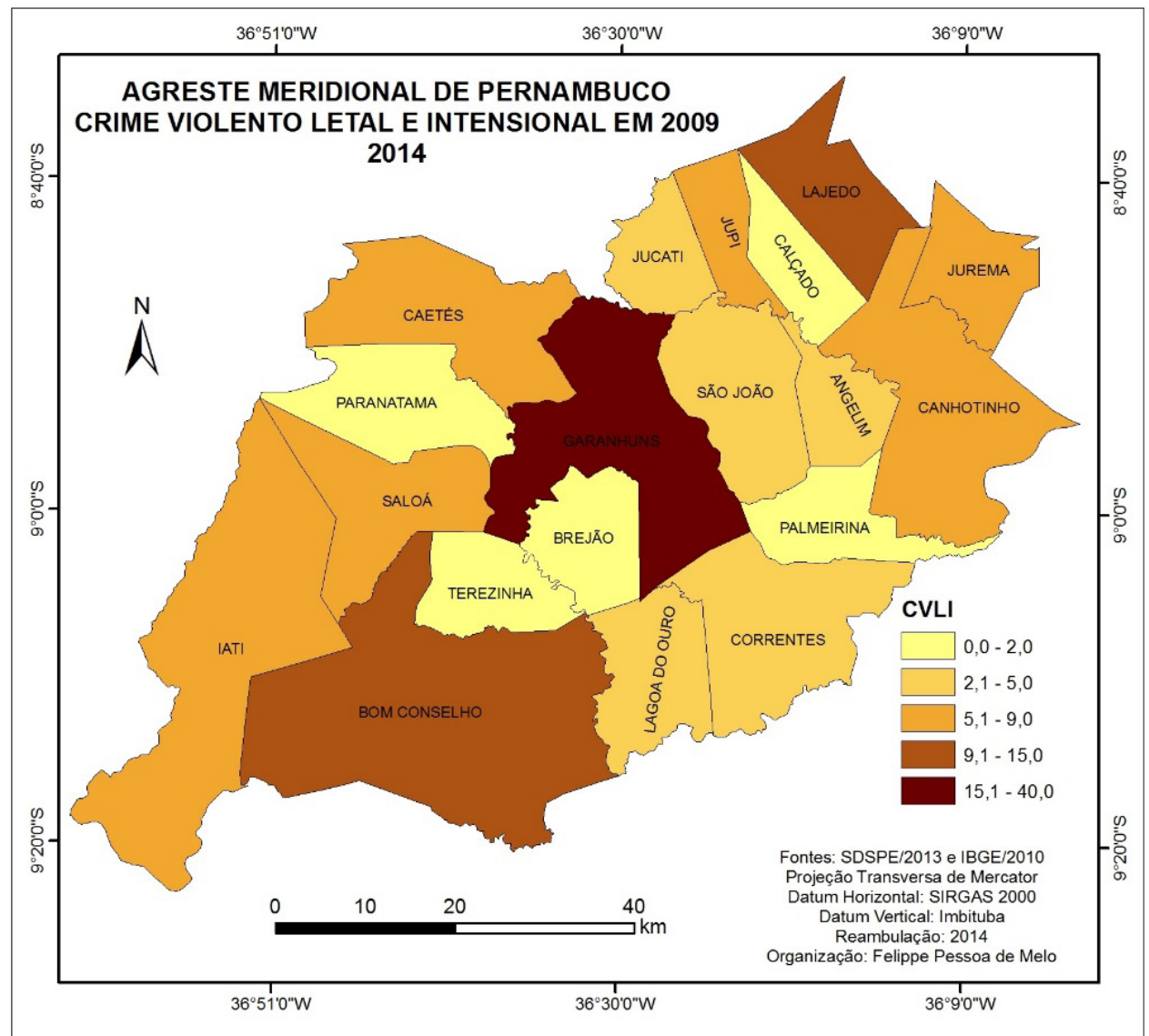

Figura 05. Índice de CVLI.

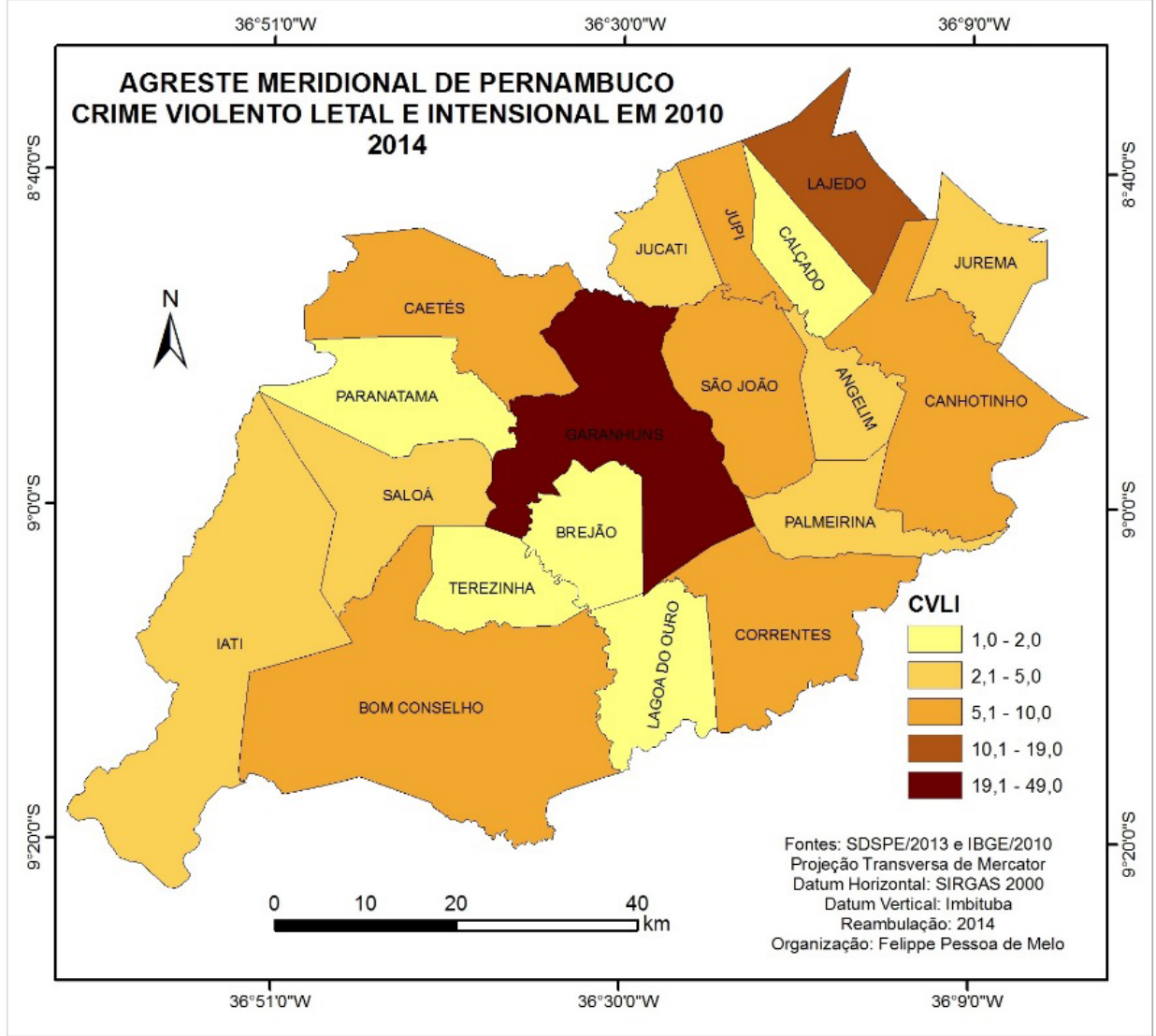

Figura 06. Índice de CVLI. 


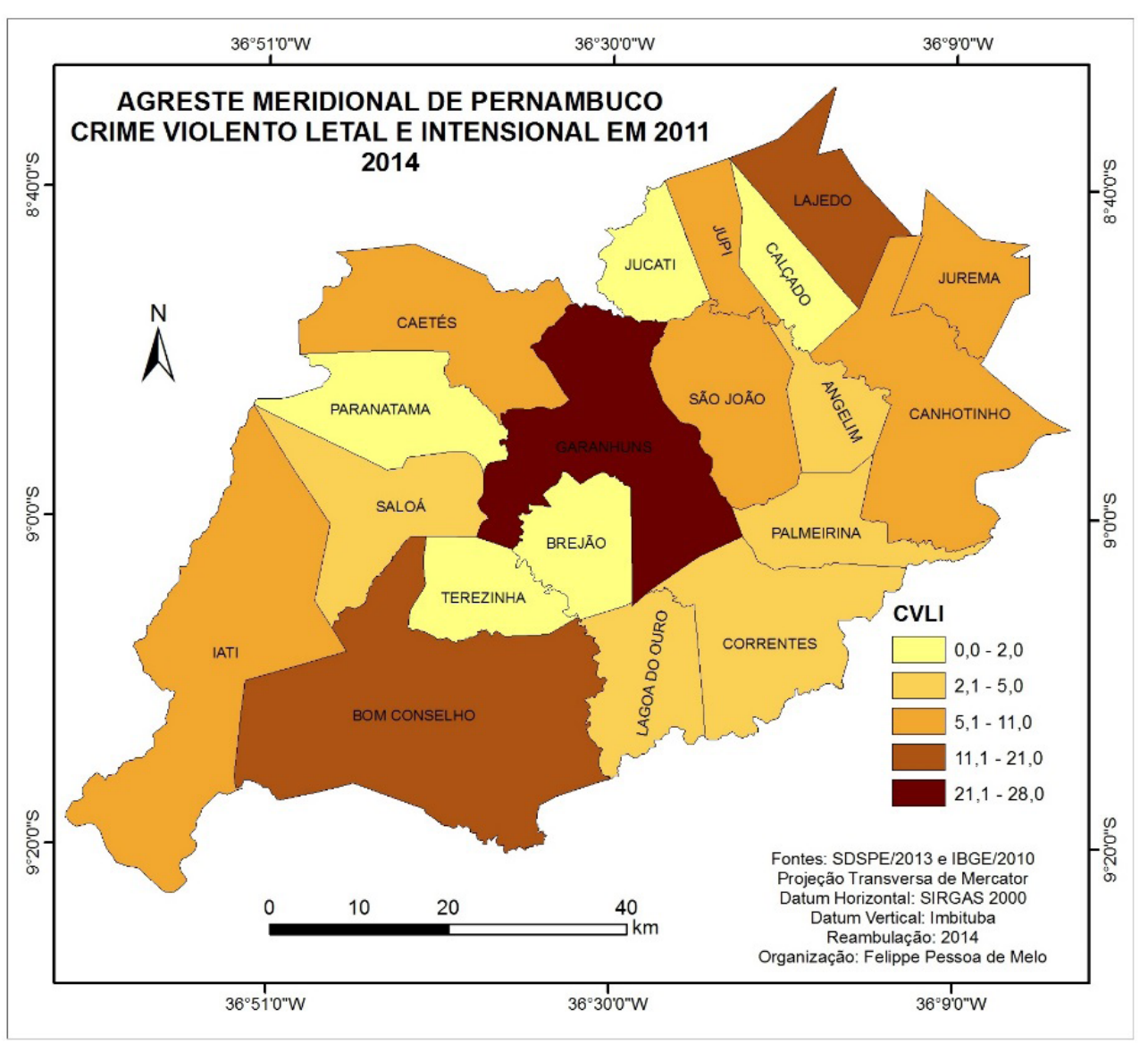

Figura 07. Índice de CVLI.

de 9,1 a 16,0 e Garanhuns chegou ao índice alarmante de 79,0.

Essa porção do território pernambucano totalizou 203 CVLI, para uma população de 442.290. Deve-se levar em consideração que $38,9 \%$ desses crimes ocorreram na cidade de Garanhuns, a qual possui uma população de 129.408 habitantes, o que representa apenas $29,2 \%$ desse montante. Desse modo, a criminalidade que ocorre em Garanhuns, é responsável por elevar de forma substancial os índices de crimes violentos letais intencionais.

No ano de 2009, Calçado, Palmeirina, Brejão, Terezinha e Paranatama, apresentaram um índice de CVLI de 0,0 a 2,0 (Figura 03); já os municípios de: Jucati, São João, Angelim, Correntes e Lagoa do Ouro, obtiveram uma taxa de 2,1 a 5,0. No mesmo período, Jurema, Canhotinho, Jupi, Caetés, Saloá e Iati, alcançaram um índice de 5,1 a 9,0; em relação a Lajedo e Bom Conselho o CVLI foi de 9,1 a 15,0; no caso específico de Garanhuns esse percentual atingiu 40,0.

No corrente ano a tríade Bom Conselho, Lajedo e Garanhuns, foram os principais responsáveis pelo o aumento da criminalidade no Agreste Meridional. O que equivale a um percentual de 48,5\%. Sendo Garanhuns responsável por 29,4\% do montante de CVLI.

Em contraposição a essa realidade, o município de Terezinha em 2009, apresentou $0,0 \%$ de crimes violentos letais intencionais. Acompanhando essa estatística, os municípios de Calçado e Paranatama, contabilizaram um CVLI cada. Visto que, Brejão e Palmeirina, também tiveram taxas baixas de criminalidade 2,0 cada.

Conforme os dados supracitados, esses quatro municípios foram responsáveis apenas por 4,4\% de todo o CVLI do Agreste Meridional em 2009.

Em 2010, Calçado, Paranatama, Brejão, Terezinha e Lagoa do Ouro, foram os municípios que apresentaram taxas entre 1,0 a 2,0 (Figura 06); Jurema, Jucati, Angelim, Palmeirina, Saloá e Iati, tiveram uma criminalidade de 2,1 a 5,0; Canhotinho, Jupi, São João, Correntes, Caetés e Bom Conselho, ficaram com um CVLI de 5,1 a 10,0; Lajedo ficou em segundo lugar na taxa de criminalidade com 19,0 crimes violentos letais intencionais e novamente Garanhuns, fica em primeiro lugar nesse índice com 49,0 . 


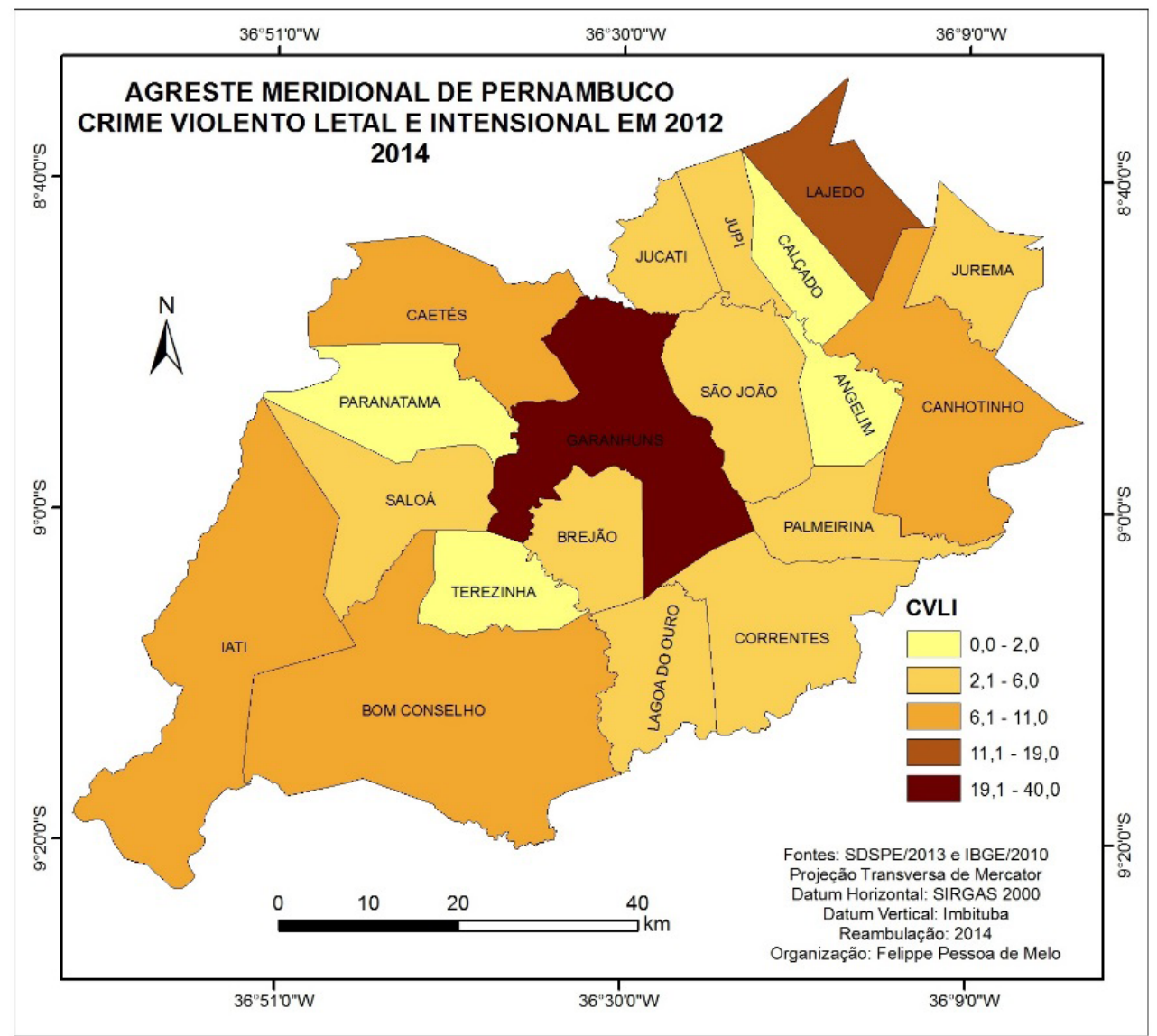

Figura 08. Índice de CVLI.

No ano de 2011, Calçado, Jucati, Brejão e Paranatama, foram os municípios menos violentos apresentaram taxas de 0,0 a 2,0 (Figura 07); Lagoa do Ouro, Correntes, Saloá, Angelim e Palmeirina, ficaram com índices entre 2,1 e 5,0; Jurema, Canhotinho, Jupi, São João, Caetés e Iati, obtiveram taxas de 5,1 a 11,0; Bom Conselho foi a terceira cidade mais violenta, com 16,0 CVLI; Lajedo, foi a segunda, com 21,0 e Garanhuns, novamente fica em primeiro lugar com 28,0.

Em 2012, Calçado, Angelim, Paranatama e Terezinha, obtiveram taxas de CVLI de 0,0 a 2,0 (Figura 08); Jurema, Jupi, Jucati, São João, Palmeirina, Correntes, Lagoa do Ouro, Brejão e Saloá, ficaram com índices de 2,1 a 6,0; Canhotinho, Caetés e Bom Conselho ficaram com taxas de 6,1 a 11,0. Lajedo foi o segundo município mais violento com um CVLI de 19,0 e Garanhuns foi o mais violento com 40,0 .

\section{CONCLUSÕES}

O Agreste Meridional configura-se uma porção do território pernambucano com uma elevada criminalidade, suas médias anuais de CVLI foram: 2008 (203), 2009 (136), 2010 (153), 2011 (137) e 2012 (143).

Com base nesses dados observa-se que de 2008 para 2009, ocorreu uma redução de 46,3\%; de 2009 a 2010, o índice de criminalidade cresce 12,5\%; de 2010 a 2011, ocorre um decréscimo de 10,4\%; de 2011 a 2012, o índice aumenta 4,3\%.

Dessa forma, de 2008 a 2012 ocorreram 772 (CVLI), o que equivale a uma média de 154,4 por ano. É necessário ressaltar que o município de Garanhuns é o principal responsável por esses índices, nas seguintes proporções: 2008 (38,9\%), 2009 (29,4\%), 2010 (32\%), $2011(20,4 \%)$ e 2012 (27,9\%).

Em contra partida o município de Paranatama, nesse mesmo intervalo temporal só apresentou 6 (CVLI), caracterizando-se o menos violento do Agreste Meridional. Deve-se ressaltar também que Calçado, no mesmo período só teve um CVLI a mais. 


\section{REFERÊNCIAS}

FREITAS, C. E. R.; VIEIRA, V. C. B. Uso do Geoprocessamento para Auxiliar a Segurança Pública no Mapeamento da Criminalidade em Teresina-PI. In: Congresso de Pesquisa e Inovação da Rede Norte Nordeste de Educação Tecnológica, 2, João Pessoa, 2007.

IBGE-Instituto Brasileiro de Geografia e Estatística. Banco de Dados. Disponível em: < http://www.ibge.gov. br/home/default.php>. Acesso em 01 de ago. 2013.

PNUD-Programa das Nações Unidas para o Desenvolvimento. Atlas do Desenvolvimento Humano. Disponível em: <http:// http://www.pnud.org.br>. Acesso em 09 de ago. 2013.

SDS/PE-Secretaria de Defesa Social de Pernambuco. Boletim Trimestral da Conjuntura Criminal. Disponível em: <http://www.sds.pe.gov.br/>. Acesso em 19 de set. 2013. 